\title{
Role of saline infusion sonohysterography in the evaluation of abnormal uterine bleeding
}

\author{
Saika Amreen, Yawar Yaseen, Naseer Ahmad Choh, Cimona Saldanha, Tariq Ahmad \\ Gojwari, Manjeet Singh
}

Correspondence: Dr Saika Amreen Department of Radiodiagnosis \& Imaging SKIMS, Soura Email - saikaamreen@gmail.com

Distributed under Attribution-NonCommercial - Share Alike 4.0 International (CC BY-NC-SA 4.0)

\begin{abstract}
Objectives: The aim of this study is to determine the accuracy of saline infusion sonohysterography in the evaluation of abnormal uterine bleeding and correlate with the histopathological findings. Methods: This study was conducted in patients with abnormal uterine bleeding refractory to medical management in a prospective manner. All patients underwent transabdominal and transvaginal sonography before sonohysterography followed by appropriate interventions. SPSS 20 and STATA 11 were used for data analysis. Results: In this study $55.2 \%$ patients underwent a dilatation and curettage while as $44.8 \%$ underwent total abdominal hysterectomy. In $65.2 \%$ patients who underwent (Total abdominal hysterectomy) TAH had few or multiple intramural fibroids. Three patients had submucous fibroids none of which were detected on TAS (Trans abdominal sonography) or TVS (Trans vaginal sonography). Saline infusion sonohysterography (SIS) detected 2 of these correctly. SIS had a sensitivity of $66.67 \%$, specificity of $95.65 \%$ and accuracy of $92.30 \%$ for adenomyosis. In $27.6 \%$ patients were found to have polyps on SIS with a sensitivity of $100 \%$, specificity of $95.4 \%$, PPV of $87.5 \%$, NPV of $100 \%$ and accuracy of $96.67 \%$. Conclusion: Saline contrast sonohysterography is a simple, safe, reliable, well-tolerated, sensitive and specific procedure for detecting focally growing lesions in the uterine cavity in women with abnormal uterine bleeding
\end{abstract}

Keywords: Abnormal uterine bleeding, transabdominal sonography, sonohysterography.

Abnormal uterine bleeding (AUB) is defined as an alteration in the volume, pattern or duration of menstrual blood flow and is the most common reason for gynecologic referrals ${ }^{1}$. It is a common cause of gynecological morbidity. In about $25 \%$ of patients, AUB is the result of a well defined organic abnormality ${ }^{2}$. Saline infusion sonohysterography has a promising role in its evaluation and assessment of the endomyometrial complex.
Saline infusion sonohysterography (SIS) was first described in 1981 by Nannini et al ${ }^{3}$. SIS provides an unparalleled, clear, enhanced view of the endo myometrial complex that cannot be obtained with transvaginal sonography (TVS) alone ${ }^{4}$. The aim of this study is to determine the accuracy of saline infusion sonohysterography in the evaluation of abnormal uterine bleeding and its correlation with the histopathological findings.

Received: $22^{\text {nd }}$ June 2019. Accepted: $20^{\text {th }}$ October 2019.

Amreen S, Yaseen Y, Choh NA, Saldanha C, Gojwari TA, Singh M. Role of saline infusion sonohysterography in the evaluation of abnormal uterine bleeding. The New Indian Journal of OBGYN. 2020; 6(2): 87-91. 


\section{Methodology}

Our prospective study was conducted in the Department of Radiodiagnosis and Imaging, SKIMS, Soura. Patients with uterine size $>12 \mathrm{wks}$, suspected or diagnosed with pregnancy, acute PID, suspected or diagnosed endometrial carcinoma, severe cervical stenosis and refusal to consent to procedure were excluded from the study. Preliminary TAS and TVS was performed to assess the appearance of the endometrium, myometrium, and adnexa. TAS was performed using a $3.5 \mathrm{MHz}$ curvilinear probe and TVS was performed using 7.5-10 $\mathrm{MHz}$ endovaginal transducer on Aloka Prosound SSD3500 SX Color Doppler Ultrasound machine and findings noted. Risks and benefits of procedure were explained and informed consent was obtained from the patient for SIS. Patient was placed in lithotomy position. The perineum was cleaned with a povidone/iodine solution. Cusco's bivalved self retaining speculum was inserted and the cervix was visualized and the external os cleansed by antiseptic solution. No 8 F Foley's catheter was flushed with sterile saline and inserted into the uterine cavity, bulb inflated with $3 \mathrm{ml}$ of normal saline \& mild traction given for confirmation. The speculum was removed. The TVS probe was reintroduced and sterile saline infused under real time guidance. Axial, coronal and sagittal imaging of the entire uterus was done and the findings noted. The balloon was deflated and the catheter gently removed. Patients were followed up for one menstrual cycle. Those who underwent surgical interventions (TAH or $\mathrm{D} \& \mathrm{C})$ were included in the study and post operative histopathological findings were used for correlation. SPSS 20 and STATA 11 have been used to analyze the data.

\section{Results}

The mean age of patients was 42.76 yrs and $37.9 \%$ patients were perimenopausal and $62.1 \%$ patients were premenopausal. Most of the patients were multiparous. The mean cycle length was 28.79 days and mean cycle duration was 6.52 days. The most common symptom was menorrhagia (91.3\%), followed by metrorrhagia (10.3\%), polymenorrhoea (8.6\%). The mean duration of symptoms was 9.12 months. The mean hemoglobin level was 9.59 $\mathrm{gm} / \mathrm{dl}$.

On TAS, endometrium could not be assessed in 7 patients, either due to obese body habitus or distorted uterine morphology. On TVS, endometrial thickness was measured in all patients where $44.8 \%$ appeared to have normal endometrium and $41.3 \%$ had increased endometrial thickness. In $6.9 \%$ the endometrial cavity appeared to split into two near the uterine fundus, suggesting arcuate uterine morphology which had remained previously unidentified on TAS.

In $55.2 \%$ patients dilatation and curettage were done while as $44.8 \%$ underwent total abdominal hysterectomy. In $65.2 \%$ patients who underwent $\mathrm{TAH}$ had few or multiple intramural fibroids. Three (11.4\%) patients had submucous fibroids none of which were detected on TAS or TVS. SIS detected 2 of these correctly. Overall, SIS detected 7 submucous fibroids in patients that were previously missed in TAS and TVS. SIS was not possible in two patients, both of which were excluded from the study. One had severe cervical stenosis and the other patient had a large intra uterine mass which made passage of the catheter impossible. An MRI was done in this patient that revealed a large polyp, filling the entire endometrial cavity, explaining the failure to catheterize the patient.

Sixteen $(27.6 \%)$ patients were found to have polyps on SIS. Of these, 13 were typical polyps, 2 had multiple polyps and 1 had a broad based polyp. Doppler evaluation of these polyps revealed the "pedicle artery sign" in 13 of these patients. Two cases were false positive, both proved to be clots.

\section{Discussion}

Saline infusion sonohysterography involves ultrasound imaging of the uterine cavity, using sterile saline solution as a negative contrast medium ${ }^{3}$. Our study included 58 women presenting AUB, refractory to medical management. $39.7 \%$ underwent SIS on day 9 of their menstrual cycle, $32.8 \%$ on day $10,24.1 \%$ on day 8 and $3.4 \%$ on day 11 . Wolman et al., compared women with abnormal bleeding who underwent SIS during the first 10 days of the cycle, with those evaluated later in the cycle. They found no false positive abnormalities in the former group, while $27 \%$ of the latter had false positive tests ${ }^{5}$.

In our study, TVS had a sensitivity of $94.12 \%$ for intramural fibroids and a specificity of $88.89 \%$. However, SIS picked up intramural fibroids in $100 \%$ of patients with a PPV of $94.44 \%$, specificity of $88.89 \%$, NPV of $100 \%$ and accuracy of $96.15 \%$. M Nass Duce et al. found that only intramural fibroids could be identified on TVS; 
The New Indian Journal of OBGYN. 2020 (January-June); 6(2)

Table 1: Comparison of various study

\begin{tabular}{|c|c|c|c|c|}
\hline Studies & Sensitivity & Specificity & PPV & NPV \\
\hline Our study & $100 \%$ & $95.4 \%$ & $87.5 \%$ & $100 \%$ \\
\hline Alcazar et al ${ }^{16}$ & $100 \%$ & $80 \%$ & $95 \%$ & $100 \%$ \\
\hline Radwan et al ${ }^{17}$ & $97.3 \%$ & $95.8 \%$ & $91.1 \%$ & $98.7 \%$ \\
\hline Yildizhan et al ${ }^{18}$ & $91.3 \%$ & $93.1 \%$ & $91.3 \%$ & $93.1 \%$ \\
\hline Aslam et al ${ }^{19}$ & $90 \%$ & $98.11 \%$ & $90 \%$ & $98.11 \%$ \\
\hline Becker et al ${ }^{20}$ & $90 \%$ & $93.1 \%$ & $81.8 \%$ & $96.4 \%$ \\
\hline
\end{tabular}

none of the submucosal fibroids were defined until after deviation of 8.6 and $\mathrm{P}$ value of .044. No false positive the introduction of saline solution in their study. They found that the addition of SIS not only shows hypoechoic, smooth rounded masses with an overlying echogenic endometrium and some degree of acoustic shadowing, but also clearly demonstrates the wall of origin, the exact localization and the extension into uterine cavity ${ }^{6}$. In our study SIS detected 7 submucous fibroids in patients that were previously missed in TAS \& TVS. Schwarzler et al. in a study found that two small submucous fibroids which had not been recognized by TVS, were detected by sonohysterography ${ }^{7}$.

In our study SIS had a sensitivity of $66.67 \%$, specificity of $95.65 \%$ and accuracy of $92.30 \%$ for adenomyosis. These patients had imaging findings of heterogenous echotexture, ill defined endo-myometrial junction, subendometrial cysts and poor endometrial distensibility. Verma et al. found that the most common sonographic finding in adenomyosis on SIS in their series was asymmetric myometrial thickening and heterogeneous echotexture ${ }^{8}$.

Endometrial polyps may be visualized at transvaginal ultrasound as nonspecific endometrial thickening ${ }^{9}$. This was found in $41 \%$ of our patients. However, SIS detected all cases of histopathologically proven endometrial polyps in our study (27.6\% of patients) with a sensitivity of $100 \%$, specificity of $95.4 \%$, PPV of $87.5 \%$, NPV of $100 \%$ and accuracy of $96.67 \%$. These values are comparable with those published in other studies (Table 1). LaiderNarin et al. in a study found that $14.8 \%$ patients with endometrial polyps would have been missed using TVS technique alone ${ }^{10}$.

The addition of doppler evaluation for the "pedicle artery sign" was found to have a sensitivity of $86.67 \%$, specificity of $100 \%$, PPV of $100 \%$, NPV of $95.56 \%$ and an accuracy of $96.55 \%$. The sign was found more often in polyps measuring more than $17.7 \mathrm{~mm}$ with a standard cases were seen. Thus, we conclude that the pedicle artery sign improves the specificity for diagnosis of endometrial polyps. Timmerman et al found that the pedicle artery test using color doppler imaging had an apparent sensitivity for detection of endometrial polyps of $76.4 \%$, specificity of $95.3 \%$, PPV of $81.3 \%$, and NPV of $93.8 \%{ }^{11}$

Six patients in our study proved to have endometrial hyperplasia, all of which had endometrial thickness of more than $10 \mathrm{~mm}$ on SIS, with a NPV of $97.14 \%$ and $\mathrm{P}$ value of .013. A meta-analysis of 85 published studies showed that an ET of greater than $5 \mathrm{~mm}$ identified $96 \%$ of endometrial cancer ${ }^{12}$.

T. Van Den Bosch et al. in their comparative study asked patients to rank the examinations in terms of pain experienced. Ultrasound examination was preferred, followed by SIS, hysteroscopy and lastly endometrium biopsy ${ }^{13}$. In $70.7 \%$ patients complained of only mild discomfort during the procedure. Only one patient described the pain as moderate while none experienced severe pain $86.2 \%$ had no complications after the procedure. Four patients had watery discharge, 2 reported spotting and mild cramping. No patients developed vasovagal syncope. Goldstein reported only three cases of a vasovagal response in a series of 1000 cases ${ }^{14}$. Patients were followed up for one menstrual cycle. None of the patients developed any complications during this period. Bonnamy et al. reported that the rate for serious complications was $1 \%$, a single case of endometritis 15 . Goldstein reported that in more than 1000 cases, he had not experienced any infectious morbidity ${ }^{14}$.

In our study group, we did not face any case with backflow problems, likely because we used a balloon catheter. Distention of the balloon on the SIS catheter helps anchor the catheter in the endometrial cavity so it is not inadvertently dislodged when removing the speculum 
or during injection and it may help occlude the internal cervical os, resulting in better distention of the cavity.

\section{Conclusion}

Saline contrast sonohysterography is a simple, safe, reliable, well-tolerated, sensitive and specific procedure for detecting focally growing lesions in the uterine cavity in women with abnormal uterine bleeding and is superior to TVS with regard to detection of polyps and submucous fibroids.

\section{Conflict of interest: None. Disclaimer: Nil.}

\section{References}

1. Garza Cavazos A, de Mola JR. Abnormal Uterine Bleeding New Definitions and Contemporary Terminology. Female Patient (Parsippany). 2012; 37: $1-9$.

2. Brenner P. Differential diagnosis of abnormal uterine bleeding. Am J Obstet Gynecol. 1996; 175: $766-9$.

3. Parsons AK. Saline infusion sonohysterography. Medica Mundi. 2001; 45: 29-41.

4. Bradley LD, Falcone T, Magen AB. Radiographic imaging techniques for the diagnosis of abnormal uterine bleeding. Obstet Gynecol Clin North Am. 2001; 27: 245-76.

5. Wolman I, Groutz A, Gordon D, Kupfermic M, Lessing J, Jaffe A. Timing of SHG in Menstruating Women. Gynecol Obs Invest. 1999; 48: 254 - 8.

6. Nass Duce M, Öz U, Özer C, Yildiz A, Apaydin FD, Çil F. Diagnostic value of sonohysterography in the evaluation of submucosal fibroids and endometrial polyps. Aust. New Zeal J Obstet Gynaecol. 2003; 43: 448 - 452.

7. Schwarzler $\mathrm{P}$, Concin $\mathrm{H}$, Berlinger $\mathrm{A}$, Wohlgenannt K, Collins WP, Bourne TH. An evaluation of sonohysterography and diagnostic hysteroscopy for the assessment of intrauterine pathology. Ultrasound Obstet. Gynecol. 1998; 11: $337-42$.

8. Verma SK, Lev-toaff AS, Baltarowich OH, Bergin D, Verma M, Mitchell DG. Adenomyosis: Sonohysterography with MRI Correlation. AJR. 2009: 192: $1112-6$.
9. Nalaboff KM, Pellerito JS, Ben-Levi E, Imaging the Endometrium: Disease and Normal Variants. RadioGraphics. 2001; 21: 1409 - 24.

10. Laifer Narin S, Ragavendra N, Parmenter EK, Grant EG. False-Normal Appearance of the Endometrium on Conventional Transvaginal Sonography. AJR. 2002; 178: 129 - 33 .

11. Timmerman D, Verguts J, Konstantinovic ML, Schoubroeck DV, Deprest, J. The pedicle artery sign based on sonography with color Doppler imaging can replace second-stage tests in women with abnormal vaginal bleeding. Ultrasound Obstet Gynecol. 2003; 22: 166 - 71.

12. Goldstein RB, Bree RL, Benson CB, Carlos R, Fleischer AC. Evaluation of the woman with postmenopausal bleeding. J ultrasound Med. 2001; 20: $1025-36$.

13. Van Den Bosch T, Verguts J, Daemen A, Gevaert O. Pain experienced during transvaginal ultrasound, saline contrast sonohysterography, hysteroscopy and office sampling: a comparative study. Ultrasound Obstet Gynecol. 2008; 31: 346 - 51.

14. Goldstein SR. Abnormal Uterine Bleeding: The Role of Ultrasound. Ultrasound Clin. 2006; 1: 415 24.

15. Bonnamy L, Marret H, Perrotin F, Body G, Berger C, Lansac J. Sonohysterography: A prospective survey of results and complications in 81 patients. Eur J Obstet Gynecol Reprod Bio. 2002; 102: 42-7.

16. Alcázar JL, Galan MJ. Transvaginal Color Doppler Sonography Versus Sonohysterography in the Diagnosis of Endometrial Polyps. J. ultrasound Med. 2004; 23: 743 - 8 .

17. Radwan P, Radwan M, Kozarzewski M, Polac I, Wilczyński J. Evaluation of sonohysterography in detecting endometrial polyps - 241 cases followed with office hysteroscopies combined with histopathological examination. Videosurgery other miniinvasive Tech. 20014; 3: 344 - 50.

18. Yildizhan B, R Yildizhan BO. Transvaginal Ultrasonography and Saline Infusion Sonohysterography for the Detection of Intrauterine Lesions in Pre- and Post-menopausal Women with Abnormal Uterine Bleeding. J Int Med Res. 2008; 36: 1205 - 13.

19. Aslam M, Ijaz L, Tariq S, Shafqat K, Kazmi T. Comparison of Transvaginal sonography and saline 
The New Indian Journal of OBGYN. 2020 (January-June); 6(2)

contrast sonohysterography in women with Abnormal Uterine Bleeding: Correlation with Hysteroscopy and Histopathology. Int J Health Sci (Qassim). 2007; 1: 17 - 24.

20. Becker E, Lev-toaff AS, Kaufman EP. The Added Value of Transvaginal Sonography Alone in Women With Known or Suspected Leiomyoma. J ultrasound Med. 2002; 21: 237 - 47.

Saika Amreen ${ }^{1}$, Yawar Yaseen ${ }^{2}$, Naseer Ahmad $\mathrm{Choh}^{3}$, Cimona Saldanha ${ }^{4}$, Tariq Ahmad Gojwari ${ }^{5}$, Manjeet Singh $^{6}$

1,3,4,5,6 Department of Radiodiagnosis \& Imaging

SKIMS, Soura; ${ }^{2}$ Medical Officer, DHSK 